\title{
A reinvindicação do espaço urbano em E se eu fosse puta, de Amara Moira
}

\author{
A Vindication of the Urban Space in And if I were a hooker, by Amara Moira \\ La reinvindicación del espacio urbano en E se eu fosse puta, de Amara Moira \\ Leandro Souza Borges Silva* \\ Ricardo Oliveira de Freitas ${ }^{* *}$
}

\begin{abstract}
Resumo
Partimos do pressuposto que o relato autobiográfico E se eu fosse puta, de Amara Moira, colabora para a compreensão da estrutura social enquanto espacialidade em constante processo de opressão e resistência. Por meio de atuação literária politicamente engajada, Amara Moira tece relatos autobiográficos que referenciam coletividades historicamente segregadas, reivindicando legitimidade literária e social. Acreditamos que notabilizar representações do urbano presente nas escritas de si permite ordenar representações íntimas da metrópole, possibilitando entender, sob uma ótica socialmente demarcada, a constituição simbólica e cultural dos espaços. A metrópole, assim, efetiva-se enquanto campo que evidencia contradições sociais pungentes, de modo que sua análise e reflexão possibilitam apreender notáveis configurações sociais. Nesse entendimento, ao estabelecer relações entre espaço biográfico e espaço urbano, são ressaltadas perspectivas a contrapelo, pois compreendemos o fenômeno literário em suas implicações sociais e políticas, propondo enfocar a obra de Amara Moira enquanto elemento que, ao defender a democratização dos espaços, privilegia o diálogo com alteridades sexualmente dissidentes.
\end{abstract}

Palavras-chave: cidade, homoerotismo, minorias, resistência.

\begin{abstract}
We take the assumption that the autobiographical report And if I were a hooker, by Amara Moira, supports the notion that the structure of society plays out as spatiality in constant process of oppression and resistance as our starting point for analysis. Through politically engaged literary action, Amara Moira weaves autobiographical reports that refer to historically segregated collectivities, claiming literary and social legitimacy. We believe that making notable representations of the urban present in writing of the self allows us to organize intimate representations of the metropolis, granting the understanding, under a socially demarcated perspective, the symbolic and cultural constitution of spaces. The metropolis, thus, becomes effective as a field that shows poignant social contradictions, in such a way that its analysis and reflection propose remarkable social configurations. Following this perspective, when establishing relations between biographical space and urban space, contrasting perspectives are highlighted, because we understand the literary phenomenon in its social and political
\end{abstract}

\section{Resumen}

Partimos del presupuesto que el relato autobiográfico E se eu fosse puta, de Amara Moira, corrobora en la comprensión de la estructura social como espacialidad en constante proceso de opresión y resistencia. A través de la actuación literaria políticamente comprometida, Amara Moira teje relatos autobiográficos que referencian colectividades históricamente segregadas, reivindicando legitimidad literaria y social. Creemos que notable representaciones del urbano presente en las escritas de si permite ordenar representaciones íntimas de la metrópoli, posibilitando entender, bajo una ótica socialmente demarcada, la constitución simbólica y cultural de los espacios. La metrópoli, así, se efectiva mientras campo que evidencia contradicciones sociales pungentes, de modo que su análisis y reflexión posibilita aprender notables configuraciones sociales. En ese entendimiento, al establecer relaciones entre espacio biográfico y espacio urbano, son resaltadas perspectivas a contrapelo, pues comprendemos el fenómeno literario en sus implicaciones sociales y políticas, proponiendo enfocar la obra de Amara Moira como elemento

\footnotetext{
" Universidade Estadual de Santa Cruz, Ilhéus, BA, Brasil. Dorcid.org/0000-0003-1856-0367. E-mail: leandroborgees@hotmail.com

** Universidade do Estado da Bahia, Salvador, BA, Brasil. (Dorcid.org/0000-0002-7528-4488. E-mail: ricofrei@gmail.com
} 
implications, proposing to focus on Amara Moira's work as an element that, in defending the democratization of spaces, privileges dialogue with sexually dissident alterities.

Keywords: city, homoeroticism, minorities, resistance. que, al defender la democratización de los espacios, privilegia el diálogo con alteridades sexualmente disidentes.

Palabras-clave: ciudad, homoerotismo, minorías, resistencia.

\section{Introdução}

A criação literária, considerada como um processo permeado por relações sociais, históricas e políticas, é passível de abrigar reflexões em torno de questões que privilegiam perspectivas dissidentes, expressões textuais que contradizem formulações discursivas hegemônicas. Dessas expressões se destacam, entre outras produções contemporâneas, os relatos autobiográficos reunidos em E se eu fosse puta, de Amara Moira. Nesse livro, a autora escancara os bastidores das relações antagônicas da urbe, caracterizando a cidade enquanto lugar de conflito e legitimação.

Travesti e prostituta, Moira incorpora em sua obra anseios e expectativas que transpassam sua subjetividade. Os capítulos do livro dão um segmento não linear à trajetória vivencial da escritora, pautando descrições que enunciam os primórdios de sua vida como travesti, apontando depois perspectivas já amadurecidas a respeito de sua vivência nas ruas. Numa linguagem desenvolta e sincera, Moira estabelece uma escrita comprometida em expressar os reveses de subjetividades recalcadas.

Nesse sentido, partindo da premissa que o cenário da literatura brasileira contemporânea é essencialmente urbano (Dalcastagnè, 2003), considera-se que os relatos da autora são relevantes por enunciarem perspectivas advindas de contextos historicamente segregados, a fim de reforçar políticas reivindicatórias em tempos de crescente ascensão de discursos excludentes e antidemocráticos. Em sendo obra subversiva, os relatos de Moira desvelam as malhas de uma organização social heteronormativa, solapando discursos engessados que se firmam em bases sociais segregacionistas.

Para a autora, a publicação de seu livro foi importante, sobretudo, para tornar públicas algumas verdades e chamar a atenção para as infrações, fragilidades e incongruências patentes numa sociedade machista. Ao transgredir as normas e legitimar uma narrativa transgressora, Moira põe seu corpo em foco e se permite desnudar em uma escrita destacadamente homoerótica. Em seu livro, os becos, ruas e vielas adquirem centralidade para expressar os perigos e prazeres de seu cotidiano como prostituta, de modo que sua experiência individual reverbera enquanto tonalidade que identifica vivências coletivas em comum.

A narrativa autobiográfica da escritora atribui à cidade sentidos antagônicos: enquanto espaço de opressão e preconceito, a rua também se estabelece enquanto território de resistência e legitimação. Nesse entender, a visada de Amara Moira possibilita compreender, por meio de sua narrativa literária, o cotidiano conflitante das travestis que, ao serem violentadas na cidade, se apropriam dos espaços como forma de autenticação de suas subjetividades. No dizer de Don Kulick (2008, p. 248): "A verdadeira mensagem que as travestis ousam transmitir é que os corpos, os desejos e as subjetividades dos brasileiros são constituídos de maneira a permitir, e até encorajar, a criação de espaços culturais como aqueles habitados por travestis".

Nesse contexto, a obra de Moira possibilita apreender destacadas relações entre os conceitos de espaço biográfico e espaço urbano, tendo em vista que suas experiências pessoais são pautadas por suas vivências nas ruas. Em sendo campo abrangente e multimodal, o conceito de espaço biográfico incorpora em seu bojo expressões transdisciplinares (Arfuch, 2010), entre as quais se insere a narrativa autobiográfica de Moira. Ao se efetuar como instância que determina a confluência de múltiplas formas e gêneros, o espaço biográfico se efetua enquanto campo de abordagem pragmático, pois ressalta a presença de elementos biográficos em variadas esferas da comunicação. 
Assim, a autobiografia de Amara Moira, ao se constituir no seio desse espaço, efetua-se enquanto escrita de si que instaura relevantes apontamentos acerca do espaço urbano. Entendido enquanto território transpassado por conflitos, a cidade é compreendida enquanto campo de tensão (Gomes, 1999) imbuído de relações sociais antagônicas por onde os sujeitos se significam. A metrópole, nesse entender, efetiva-se enquanto campo que evidencia contradições sociais pungentes, de modo que sua análise e reflexão possibilitam apreender os sentidos que dela são evocados. Por fim, tematizar a relação entre (auto)biografia e cidade, enfocando a recente publicação da supracitada autora, requer também necessários apontamentos acerca de discussões que abordem sexualidades não normativas.

\section{Escritas de si e sexualidades dissidentes: a reinvindicação do espaço urbano em $E$ se eu fosse puta}

Para Henri Lefebvre (2002, p. 10), a cidade pode ser compreendida "enquanto campo de tensões e conflitos, como lugar dos enfrentamentos e confrontações, unidade das contradições". Nesse entendimento, ao partir da relação entre literatura e cidade, considera-se relevante conceber o fenômeno literário em suas implicações político-sociais, a fim de "pensar a literatura contemporânea fora de si, atravessada por forças que a descentram e também a perfuram, sendo elas essenciais para uma definição dessa literatura que não pode nunca ser estática nem sustentar-se em especificidade alguma" (Garramuño, 2014, p. 44).

Nessa direção, ao defender a pertinência da literatura como ferramenta de análise da cidade, Pesavento (2002), por exemplo, compreende o espaço urbano enquanto unidade de sentidos. No dizer da autora, uma visada literária da cidade permite pensá-la enquanto discurso que possibilita efetuar agenciamentos simbólicos, de maneira a evidenciar a articulação de signos que elaboram a identidade cultural e social do espaço urbano. Pensar a cidade como discurso corrobora com a acepção barthesiana que promulga uma caracterização discursiva da urbe (Barthes, 2002), por onde os cidadãos constroem processos de significação em constante espelhamento. Nesse contexto, enquanto território de embates e conflitos, a cidade é composta por relações antagônicas cuja abordagem literária possibilita desvelar seus agenciamentos simbólicos e discursivos.

Por esses liames, relacionar as postulações do espaço biográfico (Arfuch, 2010) com os pressupostos do espaço urbano (Gomes, 1999; Pesavento, 2002) implica estabelecer discussões a respeito de possíveis autobiografias urbanas: quando sujeitos encampam a cidade em narrativas de cunho (auto)biográfico, enfocando, para isso, discussões que dizem respeito às sexualidades não normativas. Notabilizar representações do urbano presentes nas escritas de si permite ordenar representações íntimas da metrópole, possibilitando entender, sob uma ótica socialmente demarcada, a constituição simbólica e cultural dos espaços. A relação entre espaço biográfico e espaço urbano implica pensar, nesse sentido, em um possível espaço urbanobiográfico, no qual sujeitos se utilizam de suas narrativas pessoais para expressar singulares nuances da metrópole.

Em E se eu fosse puta, o espaço urbano-biográfico se estabelece quando Amara Moira entrelaça sua subjetividade às experiências urbanas que compõem o cotidiano das travestis. Ao tecer uma narrativa que expõe os desafios e prazeres de ser travesti nos palcos da prostituição, Moira destaca os perigos dos becos e ruas da cidade, ressaltando os momentos de medo e satisfação ao atender clientes em lugares escuros e abandonados da urbe. Em sendo expressão pessoal que reverbera vivências coletivas, Amara Moira abrange o cotidiano das travestis para mostrar ao público as faces ocultas de subjetividades relegadas ao apagamento, o que possibilita pensar a respeito de determinadas autobiografias urbanas.

Nesse contexto, a modalidade de escrita da autora implica entender sua obra como pertencente ao gênero da literatura homoerótica, apontando específicas abordagens de sua narrativa. No entender de Barcellos (2006, p. 20), o homoerotismo se estabelece como um conceito amplo que intenta "dar conta das diferentes formas de relacionamento erótico entre homens (ou mulheres, claro), independentemente das configurações histórico-culturais que assumem e das percepções pessoais e sociais que geram". No dizer do autor, a instância 
homoerótica efetiva-se independentemente da presença ou ausência de aspectos genitais, emocionais ou identitários, "tanto a pederastia grega quanto as identidades gays contemporâneas, ou ainda tanto relações fortemente sublimadas quanto aquelas baseadas na conjugalidade ou na prostituição, por exemplo".

Ao abranger relações eróticas entre pessoas do mesmo sexo, a literatura homoerótica possibilita reconhecer textos sexualmente dissidentes como constituintes de um campo múltiplo e heterogêneo. Assim, estabelecer relações entre literatura e homoerotismo possibilita efetuar abordagens até então recalcadas por discursos heteronormativos predominantes. $\mathrm{O}$ olhar homoerótico, nesse contexto, manifesta-se textualmente e aponta para outras formas de expressão literária, transpassando tanto relações pessoais quanto sociais:

A interlocução entre Literatura e Homoerotismo é, no fundo, um lugar de reflexão que, na sua materialidade discursiva acaba por privilegiar olhares diferenciados e diferenciadores como é o caso do olhar homoerótico. [...] Em outras palavras, Estudos Literários e Estudos Culturais acabam por dimensionar campos de abrangência possíveis para a dinamização de um mesmo operador: o olhar homoerótico (Souza Junior, 2007, p. 139).

O conceito de uma literatura homoerótica, nesse entendimento, rasura estruturas hegemônicas do saber e interpõe, no campo literário, inovadoras formas de abordagem. Ao descrever relações de desconforto e prazer sexual com seus clientes, Amara Moira estiliza uma escrita homoerótica destacadamente transgressora, pois denuncia as ambivalências de sujeitos que repudiam travestis ao mesmo tempo que desejam seus corpos.

Os relatos autobiográficos de Moira, nesse sentido, instauram pertinentes elaborações simbólicas da cidade por meio de sua escrita homoerótica. É relevante, nesse contexto, enviesar "uma escrita que aborda a temática homoerótica, através de um estilo marcado pela escrita de si, como possibilidade de as alteridades, muitas vezes negadas socialmente, serem também entendidas na e pela cultura brasileira" (Silva, 2014, p. 64). Enquanto alteridade que desponta no cenário literário, Amara Moira enviesa uma escrita autobiográfica que autentica a subjetividade travesti, incorporando à literatura de temática homoerótica tonalidades até então relegadas pela cultura nacional. Ao pautar seu cotidiano numa escrita intimamente engajada, a autora elucida as formas de segregação e marginalização urbana, veiculando no meio literário perspectivas dissidentes. A discriminação imputada às travestis, por exemplo, efetiva-se como um dos principais temas de seus relatos:

Gosto de andar por aí de cabeça baixa, sem ter que enfrentar olhares e imaginar o que estão pensando ao me ver. Se as pessoas riem, faço todo um esforço para acreditar que deve ser por piada ou coisa engraçada que lhes ocorreu. Me ponho num mundinho cor-derosa sempre, um que me proteja. Não olho, não retribuo olhares, passo alheia a tudo o que me envolve. E eu realmente consigo acreditar, na maioria das vezes, que essas irrupções de riso ou giros abruptos de cabeça não têm relação comigo: há sempre uma justificativa que me surja rápido, à qual me agarro sem nem precisar de esforço. Mas tem vezes que a sincronia da minha passagem com esse riso soa estranha demais, me deixa insegura, agride (Moira, 2016, p. 29).

Nota-se que circular pela cidade implica submeter-se ao repúdio social comumente perpetrado por sujeitos que negam sexualidades divergentes, de modo que andar pela urbe significa para a travesti um ato sempre desafiador, imprevisível. Assim, "a travesti sendo identificada como anormal, um monstro, passa a ser indesejada, uma ameaça à ordem, à moral e aos bons costumes, sendo vítima de violência de diversas formas, física, verbal e/ou psicológica" (Andrade, 2012, p. 114). Nessa passagem, a introspeç̧ão propositalmente infligida se estabelece como ato de defesa às formas de coação social, o que assegura as performances públicas e mantém a transgressão da travesti. Andar pelas ruas e expor uma corporeidade discordante das normas sociais se instaura enquanto forma subversiva de questionar a matriz heterossexual predatória e excludente, de maneira que esses corpos abjetos desafiam as normas da heterossexualidade compulsória (Butler, 2003). 
Em E se eu fosse puta, a subjetividade travesti problematiza suas experiências ao destacar a intolerância social, porém valida suas vivências ao rasurar premissas heteronormativas, subvertendo a cristalização dos gêneros. É importante privilegiar, nessa perspectiva, expressões que refletem "a possibilidade de subverter e deslocar as noções naturalizadas e reificadas do gênero que dão suporte à hegemonia masculina e ao poder heterossexista" (Butler, 2003, p. 60). Performar corpos fora do padrão sexual binário institui procedimentos de atuação social que solapam estruturas comumente aceitas como naturais, pondo em destaque um prisma legitimador da diversidade sexual-identitária. Nesse sentido, ao questionar discursos excludentes numa escrita íntima, Amara Moira tece relevantes figurações da cidade:

Não havia luz, só cheiro ali no mato, o matel, e as muitas, muitas camisinhas usadas pelo chão fazendo clep à medida que caminhávamos atrás dum cantinho vazio, eu de salto pisando a terra, ele empurrando a moto. Não havia luz, mas assim que ele abaixou a cueca houve cheiro, o de suor, de homem, me invadindo as narinas, dando água na boca. É ali que a gente trabalha, todas, todas, no escurinho onde der, atrás do abacateiro, ou dentro do carro do cliente quando há carro, ou no quarto do motel, pensão, se se dispõem a pagar a mais (Moira, 2016, p. 19).

Ao descrever suas experiências sexuais nos becos, vielas e periferias, a autora imbrica sua subjetividade com o espaço urbano, possibilitando notáveis vinculações entre espaço biográfico e cidade. Nesse trecho, o destaque à condição precária de trabalho constitui-se também como maneira de denunciar a marginalização da prostituição. O termo "matel", nesse contexto, ressignifica o espaço e atribui-lhe a mesma função de motel, reforçando a desvalorização das travestis prostitutas, que se veem forçadas a trabalhar em locais insalubres. A narrativa da escritora, ao pôr em foco a rua como lugar de conflito e legitimação, enviesa notáveis visadas autobiográficas de representação do urbano, corroborando com a premissa de que "Nossas cidades literárias são feitas, na verdade, de muitas ausências: mulheres, pobres [...], velhos, crianças, estão todos de algum modo excluídos das ruas e contornos urbanos que se delineiam nos textos contemporâneos" (Dalcastagnè, 2003, p. 49-50).

Ao se referir "como travesti que se descobre escritora ao tentar ser puta e puta ao bancar a escritora", Amara Moira (2016, p. 19) autentica sua posição não apenas enquanto travesti, prostituta e escritora, mas também como acadêmica. Doutora em Teoria Literária pela Universidade de Campinas (Unicamp), a autora fundamenta suas experiências sob uma visão intelectualmente comprometida, atestando que "muitos corpos escapam e a formação acadêmica se revela em uma estratégia de enfrentamento bastante poderosa" (Oliveira, 2017, p. 177). Enquanto travesti doutora, Moira figura uma exemplaridade que representa as possibilidades de ascensão e resistência de sujeitos historicamente marginalizados, enviesando discussões que privilegiam o diálogo com alteridades dissidentes, de modo a rasurar códigos heteronormativos e excludentes.

Ao se engajar numa escrita de si que reivindica cidadania, Moira tece uma expressão literária homoerótica socialmente engajada, incentivando "grupos LGBT (lésbicas, gays, bissexuais, travestis e transexuais) a transformarem a orientação sexual em bandeira de militância política" (Martins, 2010, p. 248). O espaço biográfico presente em E se eu fosse puta suscita importantes questões a respeito da segregação socioespacial na cidade, que relega sujeitos dissidentes para localidades subalternas e estigmatizadas. $\mathrm{O}$ corpo, assim, efetiva-se enquanto instância discursiva que atribui sentido às subjetividades (Butler, 2003); partindo desse pressuposto, notase que os corpos das travestis são negados e repudiados nos centros da cidade, ao mesmo tempo que são desejados nas periferias e cantos:

Travadérrima, medo de deixar quem quer que fosse se acercar de mim, mas, quando visitava as amigas na batalha, não tinha jeito, chuva de quanto você cobra, quero você, gostosa, só me diga o preço. Homens. Ali era permitido desejar meu corpo, ali, somente ali, onde esses que me desejavam eram não mais que sombras. As mais vividas, na batalha todas começam a me atiçar pra fazer a rua, ganhar o aqüé, grana, pra ficar rica (Moira, 2016, p. 31). 
Considerado abjeto em determinados locais, o corpo da travesti é desejado em outros espaços, atestando normas sociais que reservam aos sujeitos específicos lugares de circulação. Essa norma seletiva restringe aos espaços insalubres expressões sexualmente dissidentes, subalternizando as travestis como forma de assegurar a heterossexualidade vigente. Nesses locais distintos, os corpos das travestis são explicitamente desejados e buscados, o que desvela os contraditórios mecanismos de marginalização sexual. Fazer a rua, na expressão da autora, significa transitar pela urbe não apenas para ganhar dinheiro, mas para autenticar suas performances, haja vista que é somente nesses espaços segregados que suas identidades são reconhecidas. A estigmatização da experiência transsexual evidencia, portanto, que "mulheres trans e travestis, em sua maioria, têm suas experiências sociais determinadas à marginalidade, ao trabalho sexual e à violência de gênero" (Zanela, 2018, p. 379).

No entanto, a violência de gênero não encontra reações passivas e conformistas, mas, sim, respostas que resistem às formas de exclusão social. Em E se eu fosse puta, nota-se uma subversão performativa que se instaura pela erotização do espaço público, em que o sujeito transexual se utiliza da cidade como palco que valida sua constituição identitária. Ao entender a metrópole como espaço de significação, Roland Barthes (2002) comenta a respeito de uma possível dimensão erótica da cidade, entendendo por erotismo citadino as múltiplas redes de sociabilidade que podem ser estabelecidas a partir do encontro com o outro. Mais do que uma instância de prazer, o erotismo da urbe, em Barthes, supõe a possibilidade de significar o espaço a partir da troca, da transgressão: "lugar de troca das atividades sociais e eu diria quase das atividades eróticas [...] o centro da cidade é sempre vivido como o espaço onde agem e se encontram forças subversivas, forças de ruptura, forças lúdicas" (2002, p. 229).

Ao ordenar essas forças insubordinadas, os relatos de Amara Moira, nesse sentido, representam a cidade como forma de escancarar a frágil heteronormatividade, estabelecendo contundentes rupturas na heterossexualidade compulsória, termo empregado por Judith Butler (2003). No entender da filósofa e intelectual feminista, os sistemas sociais são vulneráveis em suas bordas, de modo que a homossexualidade se coloca à margem dos discursos hegemônicos, estabelecendo-se como subjetividade considerada clandestina, perigosa.

Partindo do pressuposto de que sexualidade e poder são coexistentes, Butler aponta possíveis lacunas no poder heterossexista, destacando a capacidade de subversão das travestis: "o travesti subverte inteiramente a distinção entre os espaços psíquicos interno e externo, e zomba efetivamente do modelo expressivo do gênero e da ideia de uma verdadeira identidade de gênero" (2003, p. 195). Nesse entendimento, Amara Moira estiliza uma escrita de si notadamente transgressora, tecendo relevantes comentários acerca de suas vivências na cidade: "escrever sobre a rua ao mesmo tempo em que a vivo, essa agora tão minha, essa que só meus olhos e cu e boca, essa onde eu era livre" (Moira, 2016, p. 31). Assim, a subjetividade travesti se apropria dos espaços e expressa seu cotidiano permeado pelo prazer, medo e violência:

Não sei se por estar trabalhando em texto os programas que faço (e com isso forçando uma reflexão), ou se é por a coisa ser violenta mesmo e eu só aos poucos estar me dando conta disso, a questão é que cada vez mais, cada novo cliente que me aparece, a experiência da rua se torna mais parecida com uma experiência de abuso, violência [...] (os relatos que ouço de lixo que tirou o capuz sem a travesti perceber ou que pôs arma na cabeça dela e a obrigou a dar sem), as violências verbais todas, as falas a respeito da esposa ("sou casado, então não dá pra vacilar"), tudo tem transformado radicalmente a imagem que eu fazia da prostituição (Moira, 2016, p. 95).

Enquanto atividade de sustento e socialização, a prostituição se constitui como prática que expõe as travestis às suscetibilidades da violência urbana, configurando-se como instância que legitima seus corpos ao mesmo tempo que reforça sua vulnerabilidade. Marcadas pelo desejo e pela rejeição, as travestis se veem mergulhadas num espaço imprevisível, de maneira "que é comum que travestis e mulheres transexuais evitem circular pelas ruas das cidades durante o dia e restrinjam a vivência dos espaços às noites, período do dia mais identificado com as práticas sexuais comerciais" (Pedra, 2018, p. 85). Andar pela urbe durante o dia se efetiva como ato subversivo, porém passível de opressão e violência. No dizer de Hélio Silva (2007, p. 62): 
O travesti é assim. Desviante de alta visibilidade, atrai para si todas as atenções. Desvio paradoxal, porque a própria ideia de proibido quase se confunde com a ideia de escondido, secreto. Sempre se imagina o desvio sendo cometido em vielas escuras, em sótãos sombrios, nas áreas sociais e espaços arquitetônicos periféricos, menos visíveis, pouco frequentados.

Quando esses indivíduos transitam por espaços oficiais e centrais, a norma que restringe esses sujeitos ao espaço subalterno é rasurada, de forma a causar desconforto e espanto nas camadas conservadoras. Ao compreender "as fronteiras do corpo como os limites do socialmente hegemônico" (Butler, 2003, p. 189), entende-se que estabelecer rupturas nessas fronteiras implica subverter a sedimentação das normas de gênero. Enquanto signo cultural, o corpo se efetiva como instância cuja significação é politicamente fiscalizada, de forma que a corporeidade travesti, nesse contexto, desafia as regras de regulação social. A negação do direito à cidade, assim, se dá por essas formas de violência e segregação espacial que, sendo pungentes na discriminação dessas camadas, encontra resistência na organização coletiva, que combate a transfobia e reivindica acesso à urbe (Oliveira, 2013).

Ao descrever suas experiências, Moira expõe uma corporeidade física e escritural insubmissa aos regimes de cristalização identitária, representando a urbe em suas inerentes ambivalências e contradições. Enquanto espaço de tensão e conflitos (Gomes, 1999; Pesavento, 2002), a metrópole figura nos relatos autobiográficos da escritora e atesta a multiplicidade expressiva e multimodal do espaço biográfico (Arfuch, 2010). Nesse âmbito expressivo, a narrativa da autora estabelece notáveis vinculações entre escritas de si e cidade, elucidando significações ambíguas do espaço, sendo que as travestis, "ao mesmo tempo em que confessam o desconforto com a vida difícil das ruas e da lida com os clientes, também registram que a rua é o local onde se sentem à vontade, onde podem transitar, se sentirem desejadas" (Fernandes, 2016, p. 26). Em E se eu fosse puta, nota-se que a autora destaca a rejeição perpetrada durante o dia, salientando a discriminação nos locais públicos:

Aquele momento em que você se dá conta de que estão metralhando de olhares, olhares de todos os feitios, hostis, curiosos, divertidos, zombeteiros, não você, mas a pessoa com quem você está de mãos dadas, a pessoa a quem você dedica afeto. Onde? Oras, onde você estiver, rua, metrô, ônibus, banheiro, cinema, shopping center. [...]. E tanto faz porque a culpa dessa metralhadora de olhares é sua, porque não importa quem seja a outra pessoa, importa apenas que ela está com você, travesti (Moira, 2016, p. 187).

Os relatos de Moira desvelam uma estrutura social que condena sexualidades dissidentes e nega subjetividades que se pautam pela transgressão das normas de gênero. Segundo Berenice Bento (2006), as instituições sociais (re)produzem táticas de opressão desses sujeitos, utilizandose da exposição, de insultos e do ocultamento como forma de deslegitimar indivíduos que divergem do padrão sexual binário. Repudiados enquanto corpos abjetos durante o dia, esses mesmos sujeitos são desejados à noite, em locais específicos da urbe:

Quem se permite sentir atração por nós, nossos corpos, existências? T-lovers, travequeiros, fetichistas, gente que só assume nos desejar na calada da noite, longe dos olhares públicos, gente que só consegue nos ver como aberrações. É necessário "desconstruir-se" para ser capaz de gostar de gente como nós, é necessário coragem pra nos tratar como gente. (Moira, 2016, p. 187).

Nesse trecho, a autora elucida os processos de segregação na qual limitam os espaços onde as travestis podem ser desejadas, reservando lugares específicos para expressão livre de suas identidades divergentes. Esse mecanismo de separação implica reconhecer as ambivalências do padrão heteronormativo que, em nome da manutenção do discurso hegemônico, permite-se viver a homossexualidade longe dos olhares disciplinadores que sedimentam repetidas vezes as normas de gênero.

Essas estratégias socioculturais de coação e controle dos corpos produz sujeitos reprimidos que agem em nome da preservação do status heterossexual vigente. No dizer de Guacira Lopes Louro (2004, p. 87), aqueles que transgredem as fronteiras da sexualidade, a exemplo das 
travestis, "Provavelmente serão rotulados (e isolados) como 'minorias'. Talvez sejam suportados, desde que encontrem seus guetos e permaneçam circulando nesses espaços restritos". Segundo a autora, essas minorias, tidas como ocupadoras ilegais de territórios, constituem-se como subjetividades clandestinas cuja infração deve ser penalizada.

Amara Moira reconhece essa desigual restrição dos espaços e reivindica direito à cidade, inscrevendo-se numa escrita autobiográfica politicamente engajada em favor da causa LGBTQI+. O espaço urbano-biográfico, nesse entender, pode ser percebido nos relatos da escritora, tendo em vista que sua narrativa põe em foco os conflitos vivenciados na cidade. Para Trevisan (2000), a prostituição das travestis é um preço a se pagar pela compulsória marginalidade social, tendo em vista que a experiência transexual culmina na rejeição familiar e, em sentido lato, da sociedade. Em E se eu fosse puta, a erotização do espaço urbano se efetiva como resposta a essas formas de repressão, escancarando a aparente heterossexualidade dos homens, seus desejos reprimidos e conflitantes:

Depois de gozar, possível que ele nem mais compreendesse o tesão que sentiu por mim, uma aberração, só sendo capaz de ver nojo na minha figura. Triste sina da travesti: atiçar o desejo alheio e, ao mesmo tempo, o ódio por ter despertado esse desejo. Não à toa nos matam, agridem... somos a prova viva de que ele não é tão machão padrão quanto acredita ser, quanto devia ser. Imagina se descobrem? Passado o gozo, não há mais tesão para fazer com que tenham coragem de interagir conosco: nem oi, nem tchau, sequer um sorriso. No melhor dos casos, a indiferença (Moira, 2016, p. 184).

Ao elucidar esses momentos de desejo e repulsa dos clientes, a autora prossegue sua narrativa problematizando perspectivas conservadoras, pautando visões identitárias que se afastam de discursos engessados. No entender de Barcellos (2006), o espaço urbano, enquanto território da visualidade, é propenso para que sejam aplicadas estratégias de proteção à intimidade individual, de modo que, nesse contexto, a sexualidade trans se efetiva a partir da erotização do espaço público. Quando descreve relações sexuais transpassadas de prazer e medo, Moira instaura uma escrita de si de temática homoerótica e reverbera relevantes apontamentos acerca da cidade. Ao exprimir visadas que representam um coletivo historicamente marginalizado, a autora possibilita reflexões a respeito de possíveis autobiografias urbanas, suscitando encapamentos da cidade que protagonizam sujeitos excluídos.

O espaço biográfico, em sendo campo transdisciplinar e multitemático (Arfuch, 2010), abrange notações oriundas de distintos campos discursivos, entre eles a escrita autobiográfica. Quando abarca questões relativas ao urbano, tido como território permeado por conflitos e tensões sociais (Gomes, 1999; Pesavento, 2002), essas escritas de si enviesam questões sobre um provável espaço urbano-biográfico, na qual visões metropolitanas são representadas em expressões de cunho biográfico. Em seus relatos, Amara Moira põe em evidência uma configuração espacial que, no dizer de Ferreira (2018), restringe sociabilidades à periferia das grandes cidades. Além disso, é patente que

Os espaços, do ponto de vista relacional, formam uma grade densa e complexa que impede ou dificulta que os grupos dissonantes da sexualidade hegemônica produzam seus próprios discursos espaciais, os quais são permitidos apenas em algumas circunstâncias específicas. Assim, o espaço discursivo travesti, entendido como uma trama de ações que possuem significados que são lidos e interpretados por outros grupos, é constantemente interditado (Silva, 2013, p. 158).

A interdição imputada às travestis constitui-se como maneira de perpetuar a sexualidade hegemônica, produzindo discursos que cerceiam expressões discordantes do paradigma heterossexual. Os lugares, sendo ocupados por sujeitos plurais, articulam modos e procedimentos de atuação social que se encontram em constante embate, num espaço em disputa, no qual a diferença é vista como ameaça ao padrão vigente. No entender de Pelúcio (2012, p. 410), "Essa normalização das identidades, e sua consequente opressão, define padrões de comportamento rejeitando as diferenças. Diferenças estas que são sempre constituídas em intersecção com outras.". Nessa direção, apesar da constante fiscalização dos corpos, que 
coagem travestis e demais sexualidades dissidentes, há uma constante refutação aos discursos de teor homofóbico.

\section{Considerações finais}

Ao reagir contra a violência e a discriminação, sujeitos que se pautam pela diversidade têm questionado a disciplinarização dos corpos, compartilhando suas experiências como forma de legitimar suas existências. Nesse contexto, nota-se que a diferença se instaura a partir das margens (Butler, 2003), desestabilizando estratégias sociais que intentem sabotar alteridades dissonantes. Em E se eu fosse puta, percebe-se que os espaços são ocupados como forma de autenticação das identidades marginalizadas, de modo que as travestis se apropriam e ressignificam a cidade, a fim de validar suas vivências. Esse processo de apropriação da urbe evidencia a reterritorialização dos espaços (Canclini, 1997), na qual sujeitos historicamente recalcados se apoderam da urbe para transgredir e reivindicar seus direitos, contrapondo-se à segregação e aos silenciamentos perpetrados pela organização socioespacial, conforme exemplifica o trecho a seguir:

Porém contudo todavia travesti tá aí, puta também e a gente tá um tanto cansada de ser jogada pra debaixo do tapete: vão querer continuar fingindo que a gente não existe, que isso aí não é a vida que existe pra nós? Sento, lamento e choro, não deu, não vai dar. O pai de família respeitável que atendo na zona acha um barato papar a mim por dindim poquim, o fim da picada eu contar a historinha pra deus e o mundo (Moira, 2016, p. 113).

Relatar suas histórias a deus e o mundo, para a autora, configura-se enquanto estratégia que valida suas experiências e denuncia as violências de gênero. Ao se inscrever numa obra politicamente engajada, Moira corrobora com as premissas de Silva (2012, p. 101), ao ressaltar que esses indivíduos "existem, que formam uma parcela da população, que têm direito, que reivindicam o seu 'lugar ao sol' como qualquer cidadão, sujeito cultural, ator social". A reterritorialização dos espaços, nesse sentido, implica legitimar existências negadas e atribuir destaque às travestis, compreendidas enquanto agentes culturais e sociais.

Dessa forma, nos relatos de Amara Moira, a erotização do espaço urbano efetua-se como estratégia de reterritorialização da cidade. Ao estabelecer uma escrita autobiográfica de temática homoerótica, a autora encampa as experiências das travestis e estiliza notáveis representações da metrópole. Nota-se, portanto, que o espaço urbano é representado enquanto território de embates e conflitos, mas também como lugar de resistência e legitimação de subjetividades segregadas, pois a escritora (re)significa a urbe com vias a se apropriar dos espaços e imprimir à cidade notações críticas e reivindicativas.

\section{Referências}

ANDRADE, Luma Nogueira (2012). Travestis na escola: assujeitamento e resistência à ordem normativa. Tese (Doutorado em Educação) - Universidade Federal do Ceará, Fortaleza.

ARFUCH, Leonor (2010). O espaço biográfico: dilemas da subjetividade contemporânea. Tradução de Paloma Vidal. Rio de Janeiro: EdUerj.

BARCELLOS, José Carlos (2006). Literatura e homoerotismo em questão. Rio de Janeiro: Dialogarts.

BARTHES, Roland (2002). Semiologia e urbanismo. In: BARTHES, Roland. A aventura semiológica. São Paulo: Martins Fontes.

BENTO, Berenice (2006). A reinvenção do corpo: sexualidade e gênero na experiência transexual. Rio de Janeiro, Garamond.

BUTLER, Judith (2003). Problemas de gênero: feminismo e subversão de identidade. 6. ed. Rio de Janeiro: Civilização Brasileira.

CANCLINI, Néstor García (1997). Imaginário urbanos. Buenos Aires: Eudeba. 
DALCASTAGNÈ, Regina (2003). Sombras da cidade: o espaço na narrativa brasileira contemporânea. Estudos de Literatura Brasileira Contemporânea, Brasília, n. 21, p. 33-53.

FERNANDES, Carlos Eduardo Albuquerque (2016). Um percurso pelas configurações do corpo de personagens travestis em narrativas brasileiras do século XX: 1960-1980. Tese (Dourado em Letras) - Universidade Federal da Paraíba, João Pessoa.

GARRAMUÑO, Florencia (2014). A literatura fora de si. In: GARRAMUÑO, Florencia. Frutos estranhos: Sobre a inespecificidade na estética contemporânea. São Paulo: Rocco. p. 31-48.

GOMES, Renato Cordeiro (1999). A cidade, a literatura e os estudos culturais: do tema ao problema. Ipotesi, Juiz de Fora, v. 3, n. 2, p. 19-30.

KULICK, Don (2008). Travesti: prostituição, sexo, gênero e cultura no Brasil. Tradução de Cezar Gordon. Rio de Janeiro: Fiocruz.

LEFEBVRE, Henri (2002). A revolução urbana. Belo Horizonte: Editora UFMG.

LOURO, Guacira Lopes (2004). Um corpo estranho: ensaios sobre sexualidade e a teoria queer. Belo Horizonte: Autêntica.

MARTINS, Ferdinando (2010). Cenas paralelas: do arcaico ao pós-moderno nas representações do gay no teatro brasileiro contemporâneo. In: COSTA, Horácio. Retratos do Brasil homossexual: fronteiras, subjetividades e desejos. São Paulo: Edusp.

MOIRA, Amara (2016). E se eu fosse puta. São Paulo: Hoo.

OLIVEIRA, Megg Rayara Gomes de (2017). O diabo em forma de gente: (r)existências de gays afeminados, viados e bichas pretas na educação. Tese (Doutorado em Educação) - Universidade Federal do Paraná, Curitiba.

OLIVEIRA, Tibério Lima (2013). Travestis e o direito à cidade: sujeitos transgressores em uma sociabilidade perversa. Trabalho de Conclusão de Curso (Graduação em Serviço Social) - Universidade Federal do Rio Grande do Norte, Natal.

PEDRA, Caio Benevides, (2018). Acesso à cidadania por travestis e transexuais no Brasil: um panorama da atuação do Estado no enfrentamento das exclusões. Dissertação (Mestrado em Administração Pública) Fundação João Pinheiro, Belo Horizonte.

PELÚCIO, Larissa, (2012). Subalterno quem, cara-pálida? Apontamentos às margens sobre pós- colonialismos, feminismos e estudos queer. Contemporânea, São Carlos, v. 2, n. 2, p. 395-418.

PESAVENTO, Sandra Jatahy (2002). O imaginário da cidade: visões literárias do urbano - Paris, Rio de Janeiro, Porto Alegre. Porto Alegre: Ed. Universidade/UFRGS.

SILVA, Antonio de Pádua Dias da (2012). A história da literatura brasileira e a literatura gay: aspectos estéticos e políticos. Revista Leitura, Maceió, n. 49, p. 83-108.

SILVA, Antônio Pádua Dias, (2014). A literatura brasileira de temática homoerótica e a escrita de si. Acta Scientiarum. Language and Culture, Maringá, v. 36, n. 1, p. 61-71.

SILVA, Hélio R. S (2007). Travestis: entre o espelho e a rua. Rio de Janeiro: Rocco.

SOUZA JÚNIOR, José Luiz Foureaux de (2007). Herdeiros de Sísifo: teoria da literatura e homoerotismo. Belo Horizonte: Aldrava Letras e Artes.

TREVISAN, João Silvério (2000). Devassos no paraíso: a homossexualidade no Brasil, da colônia à atualidade. Rio de Janeiro e São Paulo: Record.

ZANELA, Maria (2018). Acesso à informação para construção da cidadania de mulheres transexuais e travestis: Resoluções do Nome Social como estratégia de inclusão. Revista Brasileira de Biblioteconomia e Documentação, São Paulo, v. 14, n. 2, p. 367-396. 